\title{
DEVELOPMENT OF A NEW QUALITY FAIR ACCESS BEST VALUE PERFORMANCE INDICATOR (BVPI) FOR RECYCLING SERVICES
}

\author{
M K Harder*, N Stantzos, R Woodard, A Read
}

Waste \& Energy Research Group, University of Brighton, Lewes Rd. Brighton, BN2 4GJ

This is a post-print version of a paper which was published in Waste Management 28 (2):299309 (2008) DOI doi:10.1016/j.wasman.2006.12.015

This work is licensed under a Creative Commons Attribution-NonCommercial-NoDerivatives 4.0 International License.

\begin{abstract}
Recycling schemes are being used worldwide to reduce the impact of municipal waste. Those using public funds are usually obliged to set performance indicators by which the standards of such schemes can be measured. In the UK, a set of statutory Best Value Performance Indicators (BVPI) must be reported annually, such as the Quality of Fair Access, which monitors the public's access to recycling facilities within $1000 \mathrm{~m}$ (known as BVPI 91).
\end{abstract}

This work shows that BVPI 91, and performance indicators like it, quantify only very basic recycling services. A much more sensitive performance indicator is developed in this paper, labelled as the Maximum Practicable Recycling Rate Provision (MPRRP) achievable by a local authority. It indicates the percentage of local waste that could be reasonably recycled using the services provided, calculated on the basis of the average composition of the local waste, the local population coverage for collection of any materials, and nationally provided information stating how much of each material stream is generally suitable (practical) for recycling. Evidence for the usefulness of this new quantity is presented.

Although this paper refers a particular performance indicator in the UK, its findings are applicable to all urban areas worldwide needing to monitor recycling service. Furthermore, the MPRRP could be used for planning purposes, and for determining the level of performance of an existing service, by comparing its predicted recycling rate to that actually obtained. Further work is now being carried out on this

Keywords: Household waste, Curbside recycling schemes, Household Waste Recycling Centres, Performance Indicators.

\footnotetext{
* Corresponding author

E-mail address: m.k.harder@brighton.ac.uk

Tel: + 44-1273-642539

Fax + 44-1273-642285
} 


\section{Introduction}

\subsection{Recycling Targets}

Local Authorities in the UK are responsible for the management of municipal waste. Until recently there have been no mandatory requirements for them to increase household waste recycling, and chronic reliance on relatively inexpensive landfill has kept the national recycling rate low. For example, the cost of sending waste to landfill (including collection, transfer, transportation, operation and capital investment) was $£ 45-65$ per tonne compared to $£ 55-145$ per tonne for kerbside recycling (Department of the Environment, Transport and Regions, 1999).

In 2000 the government published Waste Strategy 2000 (Department of the Environment, Transport and Regions, 2000), which recognised the need for statutory performance standards for local authority recycling in order to meet proposed new national targets to recycle or compost $25 \%$ of household waste by $2005,30 \%$ by 2010 and $33 \%$ by 2015 . Recycling targets for individual authorities were thus introduced in April 2001 and apply to 2003/04 and 2005/06 (Adams et al., 2000). These targets were based on the previous recycling performance for each individual authority.

\subsection{Best Value Legislation \& Local Authorities}

Under the UK Local Government Act (1999), all local authorities with responsibility for waste management have been subject to the duty of Best Value. It requires local authorities 'to make arrangements to secure continuous improvements in the way they exercise their functions having regard to a combination of economy, efficiency and effectiveness.' Performance monitoring is a fundamental element of Best Value, using performance indicators such as the percentages or weights of materials recycled. Authorities are expected to derive their own individual future targets for their performance on waste, thus institutionalising target-setting in local authorities (Environmental Data Services Limited, 2000). They are now required to produce annual performance plans covering all local waste services which will be subject to inspection conducted by the Audit Commission (an independent public body responsible for ensuring that public money is spent economically, efficiently, and effectively).

The Best Value Performance Indicators (BVPI) which currently apply in the UK and are relevant to household waste and recycling are shown in Table 1. They include weights of waste recycled, composted or used to provide useful energy, and the remaining amount that goes to landfill. The amount of total waste collected per head, and its collection and disposal costs are also recorded. The remaining indicator, BVPI 91, is the one of most relevance to this work; it is the percentage of population served, either by kerbside collections or within $1 \mathrm{~km}$ of a recycling centre. A recycling centre can be any drop-off centre, from a set of bring-banks where residents may drop off recyclable materials, to a large household waste recycling centre (HWRC) where bulky household waste like furniture and tree cuttings can also be disposed of.

Although the more recent addition of BVPI 91 is an improvement over the previous lack of any similar indicator at all related to the accessibility of recycling services, it is suggested in this paper that it is an inadequate indicator that is neither sensitive nor useful beyond indicating very basic provision.

To develop ideas for more useful, alternative BVPIs this work examined the recycling services in the nearby city of Brighton \& Hove, England. Further information on the city is given in Table 2. In 2003/4, BVPI 91 was reported to be 57.5\%, yet the overall recycling rate for the city was only $16 \%$ (the recycling rate is the ratio of waste recycled to that not recycled). Brighton \& Hove City had three different kerbside schemes running in that period, two household waste 
Table 1 Best Value Performance Indicators (BVPI) for the UK relevant to household waste and recycling, and their values for Brighton \& Hove 2003/4 (Office of the Deputy Prime Minister, 2004)

\begin{tabular}{|c|c|c|c|}
\hline Indicator No & $\begin{array}{l}\text { Result } \\
\%\end{array}$ & $\begin{array}{l}\text { National } \\
\text { Average } \\
\%\end{array}$ & $\begin{array}{l}\text { Regional } \\
\text { Average } \\
\%\end{array}$ \\
\hline BV82a Household waste - percentage recycled & 13.3 & 13.2 & 16.1 \\
\hline BV82b Household waste - percentage composted & 2.7 & 3.9 & 3.0 \\
\hline $\begin{array}{l}\text { BV82c Household waste - percentage of heat, power and other } \\
\text { energy recovered }\end{array}$ & 0.0 & 10.5 & 1.5 \\
\hline BV82d Household waste - percentage landfilled & 84.0 & 71.9 & 77.7 \\
\hline BV84 Kg of household waste collected per head & 457.8 & 438.5 & 420.0 \\
\hline BV86 Cost of waste per household collection & $£ 50.9$ & $£ 38.7$ & $£ 41.5$ \\
\hline BV87 Cost of waste disposal per tonne for municipal waste & 71.4 & 39.4 & 43.9 \\
\hline $\begin{array}{l}\text { BVPI } 91 \% \text { of pop. served by kerbside collection or within } 1 \mathrm{~km} \text { of } \\
\text { recycling centre }\end{array}$ & 57.5 & 86.1 & 91.8 \\
\hline
\end{tabular}

recycling centres (HWRC) and ninety-three bring banks centres. These did not collect the same combinations of materials, making estimates of public accessibility for different materials difficult. However, BVPI 91 does not require material-specific information, so all kerbside collections and recycling centres contribute to it, regardless of the range of materials collected. For example if one household was provided with a kerbside collection service for a dozen materials and a further household only had access to a paper recycling bank within $1 \mathrm{~km}$, based upon BVPI 91 both households would meet the requirements of the indicator despite their access to recycling being very different.

Table 2 Key waste information for Brighton \& Hove City (Brighton \& Hove City Council (2004), Office for National Statistics (2004), Office of the Deputy Prime Minister (2004), Sussex Enterprise (2004))

\begin{tabular}{ll}
\hline Heading & Value \\
\hline Authority Type & Unitary \\
Population (2001) & 254,701 \\
Households (2001) & 117,525 \\
Average household size & 2.16 people per households \\
Area & 8,760 hectares \\
Population density & 29.1 people per hectare \\
GDP growth (2003) & $+2.1 \%$ \\
Unemployment rate (2003) & $2.9 \%$ \\
2003/4 recycling target & $20 \%$ \\
2005/6 recycling target & $30 \%$ \\
Recycling facilities (2003) & 0.79 recycling sites per 1,000 households \\
& $(93$ in total) \\
\hline
\end{tabular}




\begin{tabular}{ll}
\hline $\begin{array}{l}\text { 2003/04 Household waste arisings } \\
\text { Waste to landfill }\end{array}$ & Tonnes (\% of household waste) \\
$\begin{array}{l}\text { Waste to landfill from direct } \\
\text { collection }\end{array}$ & $82,024(72 \%)$ \\
Waste to landfill from HWRC & $14,082(12 \%)$ \\
Total waste to landfill & $\mathbf{9 6 , 1 0 6}(\mathbf{8 4 \%})$ \\
& \\
Recycled & $10,669(9.3 \%)$ \\
Kerbside and bring bank recycling & $5,646(4.9 \%)$ \\
Recycling at HWRC & $1896(1.7 \%)$ \\
Magpie Recycling & $72(0.1 \%)$ \\
Household fridge collection & $\mathbf{1 8 , 2 8 3}(\mathbf{1 6 \%})$ \\
Total recycling & $\mathbf{1 1 4 , 3 9 0}$ \\
\hline
\end{tabular}

\subsection{Strengths and Limitations of Performance Indicators such as BVPI 91}

Although the Local Authority has indicated its own estimate of BVPI 91, in this paper a Geographical Information System (GIS) is used to map out the data required to calculate BVPI 91 in order to investigate further possible improvements. Information from each of the three kerbside schemes is entered, and the $1 \mathrm{~km}$ distance defined in BVPI 91 is inputted as radial zones around each recycling centre in the city.

Figure 1 shows the spatial mapping of these services. It was obtained by making use of small zones defined in the 2001 Census (Office for National Statistics, UK, 2004), which contain roughly 270 people (range from 101 to 2,244, with mean at 270 at standard deviation 97) and are called Output Areas (OA) (Martin, 1998). These are the smallest units shown on the map, getting bigger towards the edges of the city. Each OA is linked to related information from the Census, such as the number of people, households and area contained within.

\section{Insert Fig. 1}

In Figure 1 the criteria for evaluating BVPI 91 is shown visually. The recycling centres are each given the prescribed $1 \mathrm{~km}$ radial zones, as specified. In many cases these overlap, with the full circular boundaries only showing near the edges of the city. Areas served by kerbside schemes are indicated separately. The resulting map shows that a very large percentage of Brighton \& Hove City residents have access to recycling services as calculated by BVPI 91, served by kerbside schemes and/or recycling centres. By making use of the underlying information of known populations in each OA unit, it is possible to use GIS to calculate that $97 \%$ of the population is served to this level. In fact, the city did not have a method in place to estimate the population served as defined by BVPI 91, and had to return values on the basis of the householders served by kerbside only, which was estimated at $57.5 \%$ in $2003 / 4$. This is in overall agreement with the GIS calculated value of $59.4 \%$ of the population served by kerbside.

\section{Insert Fig. 2}

The areas of the city which are not well serviced show up as 'recycling deserts' and are generally located on the edges of the city, where the density of the population is very much lower and the setting is semi-rural. These apparently large areas actually do not have even 3\% altogether of the population in them. However, Figure 1 shows a very different area in the east 
of the City, of higher density population (and thus with more OAs contained within) which is a 'recycling desert' - enlarged in Figure 2. This area has about 600 households, or 1,700 people. This example shows how such a performance indicator as BVPI 91 can be used to identify urban recycling deserts. However, it is much less useful as a reflection of overall recycling services. Using the BVPI 91, the distribution of recycling service currently implemented in Brighton \& Hove City appears to be very good, indicating that all of Brighton \& Hove City except for $3.2 \%$ of the population are served - a small minority.

On the other hand, the BVPI 91 does not properly reflect the overall household waste recycling rate of 16\% (2002/3) for the City, which is slightly less than the average for the South East England of $19.1 \%$ (Office of the Deputy Prime Minister, 2004). Such a performance will not be sufficient to meet the city's statutory target of a $30 \%$ rate by $2005 / 06$. In addition, the city faces acute problems of declining landfill space as the existing local sites are projected to be full. (Environment Agency, 2002). There is thus significant pressure on the Local Authority of this city and others to quickly gain an understanding of how to increase their recycling rates. But the current formal performance indicators such as BVPI 91 do not provide useful information to assist this process.

In this paper, information on the various recycling services in the City is looked at in more detail, including both the material types collected and the distances residents have to travel to recycling centres. This work is greatly aided by the use of the Geographical Information System (GIS), which allows the overlap of multiple layers defined by the operator. It is used to consider various data sets and options for performance indicators, as discussed below.

One weakness of the current performance indicator, BVPI 91, is that is does not distinguish between services for different materials, e.g. paper, glass. This means that authorities who collect many materials are currently rated the same as those which collect only one. In this work GIS is used to examine the variation of recycling services by material type for Brighton \& Hove City, to determine whether they suggest better performance indicators for future use. Another issue investigated here is the realistic distance that residents will travel to use recycling centres, relative to the $1 \mathrm{~km}$ used in BVPI 91. Finally, some options for more useful indicators are discussed.

\section{GIS investigation of recycling services}

\subsection{Site information}

For each Output Area (OA), demographic information for Brighton \& Hove City such as population, number of households and area are provided by the Office of National Statistics (ONS) based on Census 2001 data. Output Areas (OAs) are the main geographic-based format used by the ONS for Census data and are compatible with GIS applications (Martin, 1998).

Each bring bank and the two HWRCs in Brighton and Hove City were surveyed and their exact locations were recorded using a Global Positioning System (GPS). Information such as the types of materials collected at the site, the number and capacity of containers and the overall condition of each site were also recorded.

The area of each kerbside scheme was mapped by assigning the relevant postcodes to the streets served. Information about the areas covered by the kerbside schemes and the materials collected was supplied by Brighton and Hove City Council Recycling Services. 
In addition to Council initiatives there exists a non-profit community recycling organisation called Magpie which also offers a kerbside collection scheme. This scheme has been in operation for over ten years operating on a subscriber basis where people volunteer to pay to have their recyclables collected. At the time, Magpie had about 4,600 customers and collect a variety of materials (glass, paper, cardboard, plastic bottles, tins, metal foil, textiles and tetrapak cartons). Although Magpie focuses on serving areas in central Brighton \& Hove City, they also collect from outer areas, and all service areas include many non-customers. Such communitybased recycling initiatives are valuable both in terms of tonnages of materials collected and diverted from landfill as well as in terms of increasing awareness about recycling and waste management. However, the Magpie service was not included in our analysis because participants have to pay to have their recyclables collected. This makes it ineligible to contribute towards the Council's performance indicator, BVPI 91. The tonnages they collect are reported to the authority and in 2003/4 contributed around 2\% towards the city's $16 \%$ overall household recycling rate.

\subsection{GIS application of data}

The point-by-point information of the location of each recycling centre was mapped into a Geographic Information System (GIS) in layers, with a $1 \mathrm{~km}$ zone defined around each. Similarly, layers were produced mapping the various kerbside schemes. These layers could then be interrogated spatially, e.g. by laying layers over each other and considering the combined areas serviced by kerbside schemes and/or recycling centres, for each material or combination of materials.

The resulting information summarising all materials and all services has already been shown in Figure 1, and a close-up of one of its recycling 'deserts' in Figure 2. In Figures 3a-f, the spatial analysis of services for each material type are now shown separately for paper, glass, textiles, cardboard, plastics and cans. The method used to estimate the populations served in a given 'service area' is presented in detail on the website www.brighton.ac.uk/WERG. It involves breaking the City down into convenient polygons with OA's within and overlapping them, and which have a rigorous calculation of the population in each.

\section{Insert Fig. 3 A-F}

\section{GIS Analysis of Accessibility of Services}

\subsection{Kerbside and Recycling Centre Services}

The method for estimating populations in various service areas is applied to the GIS spatial information - for example as in Figure 1 which was used to show overall recycling services. The population analysis shows that $59 \%$ of the population are served by a kerbside scheme, and almost all of those also have access to recycling centres within $1 \mathrm{~km}$. Thirty eight percent of the population live within $1 \mathrm{~km}$ of a recycling centre - including some who are not on a kerbside scheme. Overall, this GIS analysis shows that $97 \%$ of the population is offered at least one form of recycling service (see Table 3 ).

\subsection{Services for Different Materials}

The spatial information in Figures 3a-f was used to show information on individual materials collected, and can be combined with the population estimation method described on the web site to calculate the quality of service provided for each material. This is summarised in Table 3 . It is evident that recyclable materials such as paper, glass and cans have very good provision with about $97 \%$ of population served by either kerbside or recycling centres. Textiles are also well covered at $92 \%$. However, the situation is rather different for plastic bottles and cardboard. 
There are no bring banks accepting plastic, and it is only collected on one of the kerbside schemes. This leaves the majority of Brighton \& Hove's population (68\%) without an equivalent plastics recycling service. Cardboard is also collected in one of the kerbside schemes, and through a network of ten bring banks. However, this network is very much smaller than those for other materials, leaving $46 \%$ of the population further than $1 \mathrm{~km}$ from a recycling facility.

Table 3 Percentage of population with access to recycling services catering for various materials, calculated using GIS (Brighton \& Hove City Council (2004), Office for National Statistics (2004))

\begin{tabular}{|c|c|c|c|c|c|c|c|}
\hline Service: & $\begin{array}{l}\text { Access } \\
\text { to either } \\
\text { kerbside } \\
\text { scheme } \\
\text { or } \\
\text { recycling } \\
\text { centre } \\
(\%)\end{array}$ & $\begin{array}{l}\text { No } \\
\text { access to } \\
\text { kerbside } \\
\text { scheme } \\
\text { or } \\
\text { recycling } \\
\text { centre } \\
(\%)\end{array}$ & $\begin{array}{l}\text { Access } \\
\text { to } \\
\text { kerbside } \\
\text { scheme } \\
(\%)\end{array}$ & $\begin{array}{l}\text { Access } \\
\text { to } \\
\text { kerbside } \\
\text { scheme } \\
\text { only } \\
(\%)\end{array}$ & $\begin{array}{l}\text { Access } \\
\text { to } \\
\text { recycling } \\
\text { centre } \\
(\%)\end{array}$ & $\begin{array}{l}\text { Access } \\
\text { to } \\
\text { recycling } \\
\text { centre } \\
\text { only }(\%)\end{array}$ & $\begin{array}{l}\text { Access } \\
\text { to both } \\
\text { services } \\
(\%)\end{array}$ \\
\hline \multicolumn{8}{|l|}{ Material } \\
\hline Paper & 97 & 3 & 59 & 1 & 96 & 38 & 59 \\
\hline Glass & 97 & 3 & 44 & 2 & 96 & 54 & 43 \\
\hline Cans & 97 & 3 & 42 & 1 & 96 & 55 & 41 \\
\hline Textiles & 92 & 8 & 32 & 3 & 89 & 60 & 29 \\
\hline Cardboard & 54 & 46 & 32 & 18 & 36 & 22 & 14 \\
\hline Plastics & 32 & 68 & 32 & 32 & N/A & N/A & N/A \\
\hline $\begin{array}{l}\text { Garden } \\
\text { Waste }\end{array}$ & 12 & 88 & N/A & N/A & 12 & 12 & 12 \\
\hline $\begin{array}{l}\text { Any } \\
\text { Material }\end{array}$ & 97 & 3 & 59 & - & 96 & - & 59 \\
\hline
\end{tabular}

Garden waste is only collected at the two Household Waste Recycling Centres, as shown in Figure 4, leaving large areas of the city without easy access. Research by Williams and Taylor (2004) shows that the majority of site users visit these facilities by car, so the $1 \mathrm{~km}$ zone used for the calculation of the BVPI 91 is not necessarily a reflection of real practice. Typical values for the distances travelled by residents using the garden waste recycling facilities are not available for Brighton \& Hove City, but a recent study using a sample of 1000 visitors to the nearby town of Eastbourne gave an average distance of $2.7 \mathrm{~km}$ (standard deviation of $1.5 \mathrm{~km}$ ). A zone of 2.7 $\mathrm{km}$ around the garden waste facilities is thus also shown in Figure 4 for reference. Regardless which of the different sized zones are used, Figure 4 clearly shows that the city does not provide garden waste recycling facilities across the whole population.

The clearly uneven provision across the City of different materials as shown in Figures 3 and 4 is not reflected in the crude performance indicator commonly used - BVPI 91 - which suggests excellence with a value of $97 \%$. Indeed, Figures 3 and 4 appear more closely linked to the recycling rate of $16 \%$ which was achieved. This approach thus warranted further investigation towards development of a more useful performance indicator. 
A similar issue arises when trying to determine what the realistic, reasonable distance is for residents to travel to bring banks to deposit recyclable materials. The current BVPI 91 implies that $1 \mathrm{~km}$ is reasonable. However Belton et al., (1994) suggested that the average distance residents were willing to travel by foot to a recycling centre was $640 \mathrm{~m}$. Clearly, this is very different to the $1 \mathrm{~km}$ currently calculated. Unless recycling centres are designed to be used considerably for car drop-offs, estimating their effective zone at $1 \mathrm{~km}$ appears inappropriate. A truer picture of effective recycling service provision would be seen using zones of about 640m. The results of such analysis are given below in Table 4. As would be expected the accessibility to recycling facilities reduces for those materials that are essentially collected through recycling centres. For example access to textile and cardboard recycling facilities reduces by $15 \%$ and $8 \%$ points respectively when the coverage is reduced to $640 \mathrm{~m}$. However, the incorporation of these more realistic parameters to the original performance indicator, BVPI 91, only changes its reported value from $97 \%$ to $94 \%$ - it simply is not sensitive enough, even with such changes.

Table 4 Access to recycling services in Brighton and Hove City when the BVPI 91 distance reduces to $640 \mathrm{~m}$

\begin{tabular}{|c|c|c|c|c|c|c|c|}
\hline Service: & $\begin{array}{l}\text { Access to } \\
\text { either } \\
\text { kerbside } \\
\text { scheme } \\
\text { or } \\
\text { recycling } \\
\text { centre } \\
(\%)\end{array}$ & $\begin{array}{l}\text { No access } \\
\text { to } \\
\text { kerbside } \\
\text { scheme } \\
\text { or } \\
\text { recycling } \\
\text { centre } \\
(\%)\end{array}$ & $\begin{array}{l}\text { Access } \\
\text { to } \\
\text { kerbside } \\
\text { scheme } \\
(\%)\end{array}$ & $\begin{array}{l}\text { Access } \\
\text { to } \\
\text { kerbside } \\
\text { scheme } \\
\text { only }(\%)\end{array}$ & $\begin{array}{l}\text { Access to } \\
\text { recycling } \\
\text { centre } \\
(\%)\end{array}$ & $\begin{array}{l}\text { Access to } \\
\text { recycling } \\
\text { centre } \\
\text { only }(\%)\end{array}$ & $\begin{array}{l}\text { Access } \\
\text { to both } \\
\text { services } \\
(\%)\end{array}$ \\
\hline \multicolumn{8}{|l|}{ Material } \\
\hline Glass & 94 & 6 & 44 & 8 & 86 & 49 & 37 \\
\hline Paper & 93 & 7 & 59 & 8 & 85 & 34 & 52 \\
\hline Cans & 90 & 10 & 42 & 6 & 84 & 49 & 36 \\
\hline Textiles & 77 & 23 & 32 & 18 & 59 & 45 & 14 \\
\hline Cardboard & 46 & 54 & 32 & 27 & 19 & 14 & 6 \\
\hline Plastics & 32 & 68 & 32 & 32 & N/A & N/A & N/A \\
\hline $\begin{array}{l}\text { Green } \\
\text { waste }\end{array}$ & 6 & 94 & N/A & N/A & 6 & 6 & 6 \\
\hline $\begin{array}{l}\text { Any } \\
\text { material }\end{array}$ & 94 & 5 & 59 & & 86 & & 52 \\
\hline
\end{tabular}

\section{Performance Indicators for 2004/5 and Beyond}

\subsection{Justification for new BVPIs}

The data presented has indicated that the current performance indicator used to measure recycling services of local authorities is not sensitive to provision beyond basic services. However, it is important that local authorities are free to develop recycling services suited to the needs of their residents, so it is not appropriate for alternative BVPIs to dictate exactly which materials are collected, or how. For example, one authority may have excellent demand from local manufacturers to make use of recycled styrofoam so they collect it while others would not. Unusual variations like this would not be disadvantaged by this BVPI. 
This leaves the question of how to devise a new performance indicator which will indicate the quality and breadth of recycling provision by the local authorities but remains practical. In this paper an examination of the typical composition of household waste suggests another approach. This approach takes into the account the local conditions and sets benchmarking targets accordingly, and is outlined below.

If the national UK recycling target of $25 \%$ for $2005 / 6$ is to be met, it is reasonable to expect all authorities will need to provide facilities capable for recycling at least 40-50\% of waste thrown out (since not all households will participate, the actual recycling rate will be lower). At the same time, residents will be demanding that a significant percentage of their waste is provided with facilities for recycling, especially as they are put under greater pressure to reduce their residual waste. If residents are going to make an effort, they will want the services to be significant, not just a token collection service like paper on its own. These lines of thought lead to the same idea - a new performance indicator which measures how much of the household waste has the potential to be captured by the authority's facilities - their Maximum Practicable Recycling Rate Provision (MPRRP).

Table 5 provides an example of the waste composition both locally and nationally and highlights how analysis for such a performance indicator could be carried out specifically for kerbside recycling. The essence of this approach is to take into consideration local conditions and the reasonable actions that could be expected from residents.

The example of paper and cardboard helps to explain the new indicator. The starting point for the indicator is the composition of the waste stream from waste collected directly from households. Paper and cardboard both nationally and locally is the abundant material in the waste stream at $32 \%$. However not of this material is suitable for recycling. For example the paper may be soiled or comprise of tetrapak drinks cartons which most authorities do not recycle in the UK. The government has published information on the recyclability of household waste and according to their guidance only $65 \%$ of paper and cardboard is recyclable in the kerbside scheme (Department of the Environment, Transport and Regions, 2000). Therefore only a maximum of $21 \%$ of the household waste stream could contribute from direct collections of recyclable paper and cardboard in Brighton \& Hove City.

However, there are other factors to take into consideration. At present only $59 \%$ of the total population have access to a kerbside paper service, which reduces the total paper and cardboard portion of the waste stream that could be collected through a kerbside scheme to $12 \%$. This assumes that all residents will participate, and place all paper and cardboard out for recycling. Research by the Open University uses an $85 \%$ participation rate and a separation efficiency of 65\% (Open University, 2003). Thus, despite paper and cardboard representing 32\% of the waste stream, these levels of participation and separation make it reasonable to predict that only $7 \%$ would actually be captured for recycling through a UK kerbside service:

$32 \%$ of waste is paper $\times 65 \%$ paper is recyclable $\mathrm{x} 59 \%$ population has service $\mathrm{x} 85 \%$ people participate $\mathrm{x} 65 \%$ of the eligible material is separated for recycling by the householder $=7 \%$ MPRR for paper.

If similar calculations are carried out not just for paper but for all of the recyclable materials in the household waste stream, as shown in Table 5, then a grand total of $10 \%$ is found to be the overall MPRR (Maximum Practical Recycling Rate for Brighton \& Hove City kerbside scheme). 
To investigate how sensitive this approach is to local data the MPRR is calculated again for Brighton \& Hove City but this time assuming that the composition of waste is as reported in general for the UK, rather than as measured locally. Assuming, the same coverage, participation rate and separation efficiency the maximum practicable recycling rate would be very similar $11 \%$ (see Table 5). Thus, even this approximation does not greatly affect the MPRR, which is important, as some authorities may not yet have obtained local analysis of the composition of their waste and may need to use national values.

In order to gauge how close to reality the MPRR is, it is useful to use it to derive a calculated Recycling Rate for the City. The Recycling Rate is the ratio of the household waste that is recycled (or composted) compared to that not recycled (or composted). It includes not only the waste picked up from the household kerbside service, but also that deposited in Household Waste Recycling Centres (HWRC) and via non-municipal schemes such as Magpie in Brighton $\&$ Hove. These contribute $5 \%$ and $2 \%$ respectively to the Recycling Rate, which, when combined with the MPRR of $10 \%$ calculated here for the kerbside, gives $17 \%$. This value is totally consistent with the measured value for the City of $16 \%$ (both have uncertainties of the order of $1 \%$ ), and thus suggests that the existing kerbside services are performing well.

Table 5 Summary of maximum practicable recycling rate provision from kerbside recycling schemes for Brighton \& Hove City, using reported city waste composition for 2003/4 (i) (Ecosys, 2003) and using reported UK national waste composition (ii) (Parfitt, 2002).

\begin{tabular}{|c|c|c|c|c|c|c|}
\hline & $\begin{array}{l}\text { A } \\
\text { Composition } \\
\%\end{array}$ & $\begin{array}{l}\text { B } \\
\text { Recyclable } \\
\%\end{array}$ & $\begin{array}{l}\text { C } \\
\text { Recyclable } \\
\text { element \% }\end{array}$ & $\begin{array}{l}\text { D } \\
\text { Households } \\
\text { covered \% }\end{array}$ & $\begin{array}{l}\mathbf{E} \\
\text { Recyclable } \\
\text { after coverage }\end{array}$ & $\begin{array}{l}\text { F } \\
85 \% \\
\text { participatio }\end{array}$ \\
\hline $\begin{array}{l}\text { i) } 2003 / 04 \\
\text { using local } \\
\text { composition }\end{array}$ & & & $\mathrm{A} / 100^{*} \mathrm{~B}$ & & $\mathrm{C} / 100 * \mathrm{D}$ & $\mathrm{E} / 100 * 85$ \\
\hline Paper and card & 32 & 65 & 21 & 59 & 12 & 10 \\
\hline Glass & 8 & 90 & 7 & 44 & 3 & 3 \\
\hline Plastics & 6 & 33 & 2 & 32 & 1 & 1 \\
\hline Metals & 4 & 95 & 4 & 42 & 2 & 1 \\
\hline Textiles & 3 & 95 & 3 & 32 & 1 & 1 \\
\hline Total & 53 & & 36 & & 15 & 13 \\
\hline \multicolumn{7}{|l|}{$\begin{array}{l}\text { ii) } 2003 / 04 \\
\text { using national } \\
\text { composition }\end{array}$} \\
\hline Paper and card & 32 & 65 & 21 & 59 & 12 & 10 \\
\hline Glass & 9 & 90 & 8 & 44 & 4 & 3 \\
\hline Plastics & 6 & 33 & 2 & 32 & 1 & 1 \\
\hline Metals & 8 & 95 & 8 & 42 & 3 & 3 \\
\hline Textiles & 2 & 95 & 2 & 32 & 1 & 1 \\
\hline Total & 57 & & 40 & & 20 & 17 \\
\hline
\end{tabular}


The examples shown above indicate that the overall MPRR is a useful performance indicator, which is sensitive to details of household provision including details of the types of materials collected. It requires as an input information on population coverage which is generally available to authorities via census data, and geographical information on recycling schemes such as collection routes, which all authorities will have. By combining these in a GIS application, the MPRR can be calculated - sensitive performance indicator. Although it is more accurate when derived from local data on waste composition, it is still sensitive when using nationally provided average data.

An important strength of the MPRR is that its definition does not prejudice local authorities towards or against any particular recyclable materials, or particular collection or recycling methods. This allows them the freedom to pursue local opportunities and to respond to local pressures and preferences. It is suggested here that the overall MPRR is worthy of adoption as a sensitive, practical and useful performance indicator for recycling services.

Of all the materials in the waste stream, paper \& card is the largest contributor by weight (32\% for Brighton \& Hove) and is ubiquitous. It is thus fundamental to the success of any recycling scheme that facilities are provided for its collection. A measure of the services provided for this material alone would actually provide an excellent broad performance indicator in the same way as the current BVPI 91 does. To the extent that such a parameter is useful, it would be sensible to use the MPRR for paper for the old BVPI 91, as it will be calculated anyway in the derivation of the overall MPRR which is the sensitive and more useful performance indicator.

\section{Conclusion}

This work has indicated that Best Value Performance indicator, BVPI 91, currently used in the $\mathrm{UK}$, is not sensitive to the quality of service provisions for recycling beyond basic provisions for any one material. The current indicator gives values of $97 \%$ for the sample city of Brighton \& Hove, which only has a recycling rate of $16 \%$.

If a performance indicator is intended to measure the accessibility of householders to recycling facilities beyond basic provision, it is crucial that it takes into account the relative contribution of different materials to household waste. The current BVPI 91 is so basic that it could successfully be replaced with any rough measure of the dominant recycled material - paper \& card.

For a more sensitive and useful indicator of recycling services to the public, it is suggested that a different quantity be reported. This is developed and labelled here as the 'Maximum Practicable Recycling Rate' (MPRR) achieved by local authorities. It is calculated on the basis of nationally provided information stating how much of each recyclable material is deemed suitable (practical) for recycling and their separation efficiency, and on locally obtained information on participation rates, population coverage for the collection of each material, and the average composition of the local waste. In cases where the latter is not known a national average composition can be used to a good approximation.

A calculation of this quantity is provided for the example of Brighton \& Hove, making use of a Geographical Information System (GIS) to link service provision with population numbers. The detailed method used to do this is presented on our web site, and it enables easy and accurate 
calculation of the proposed new performance indicator, MPRR. As most local authorities have GIS facilities and access to Census data in the developed world, this process should not be onerous or unreasonable to carry out annually with other BVPI calculations, and will likely lead to better waste management planning in authorities around the world through more careful consideration of their own local data.

A sub-component of the overall MPRR, i.e. the MPRR for paper \& card, can be used as a nonsensitive measure of the breadth of recycling services to directly replace the old BVPI 91, if it is considered to still serve a useful purpose. 


\section{References}

Adams, K. T., Phillips, P., and Morris, J.R. (2000) A radical new development for sustainable waste management in the UK: the introduction of local authority Best Value legislation. Resources, Conservation and Recycling, 30, 221-244.

Belton, B., Crowe, D., Matthews, R., and Scott, S. (1994) A survey of public attitudes to recycling in Glasgow (U.K.). Waste Management \& Research, 12, 351-367.

Brighton \& Hove City Council (2004) Sustainability waste 2004-2006, Brighton \& Hove City Council, Brighton, UK

Department of the Environment, Transport and Regions (1999) A Way With Waste. A Draft Waste Strategy for England and Wales. HMSO, London, UK.

Department of the Environment, Transport and Regions (2000) Waste Strategy 2000 for England and Wales. HMSO, London, UK.

Ecosys (2001) Brighton and Hove City Council Household Waste Analysis March 2001. Ecosys, Brighton, UK.

Environment Agency (2002) The problem with waste in Sussex. www.environmentagency.gov.uk Accessed 21 Feb 2003

Environmental Data Services Limited (2000) Best Value highlights consultation as key to municipal waste strategies. ENDS, 307, 34-35.

Local Government Act (1999) HMSO, London, UK.

Martin, D (1998) 2001 Census output areas: from concept to prototype. Office of National Statistics, Population Trends, 94, 19-24

Office for National Statistics (2004) Census 2001-Brighton \& Hove Local Authority Profile, www.statistics.gov.uk/census2001, Accessed 11 June 2004

Office of the Deputy Prime Minister (2004) Local Government Performance - Key Facts for 'Brighton \& Hove' 03/04, www.bvpi.gov.uk, Accessed 16 June 2004.

Open University (2003) Developing Integrated Waste Management Strategies: Information needs and the role of locally-based data. Integrated Waste Systems, The Open University, Milton Keynes, UK.

Parfitt, J. (2002) Analysis of household waste composition and factors driving waste increases. Waste and Resources Action Programme, Banbury, UK.

Sussex Enterprise (2004) Annual Economic Review 2004, www.sussexenterprise.co.uk, Accessed 14 June 2004.

Williams, I. D. and Taylor, C. (2004) Maximising household waste recycling at civic amenity sites in Lancashire, England. Waste Management, 24 (9), 861-874. 


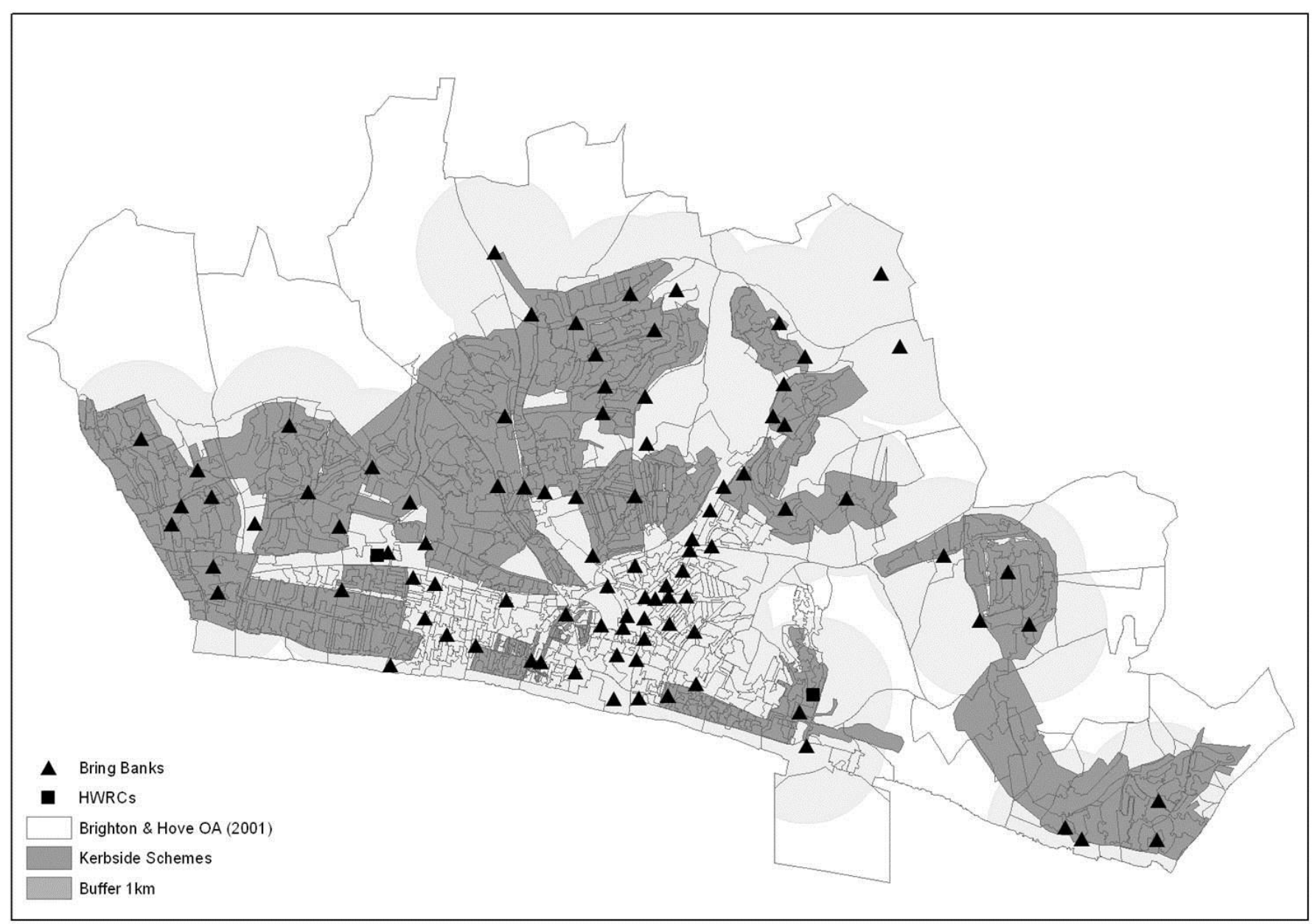

Fig. 1. Spatial information on Brighton \& Hove City (Office for National Statistics, 2004), showing Output Areas with indications of their population densities from Census 2001, overlaid with the coverage of recycling services. 


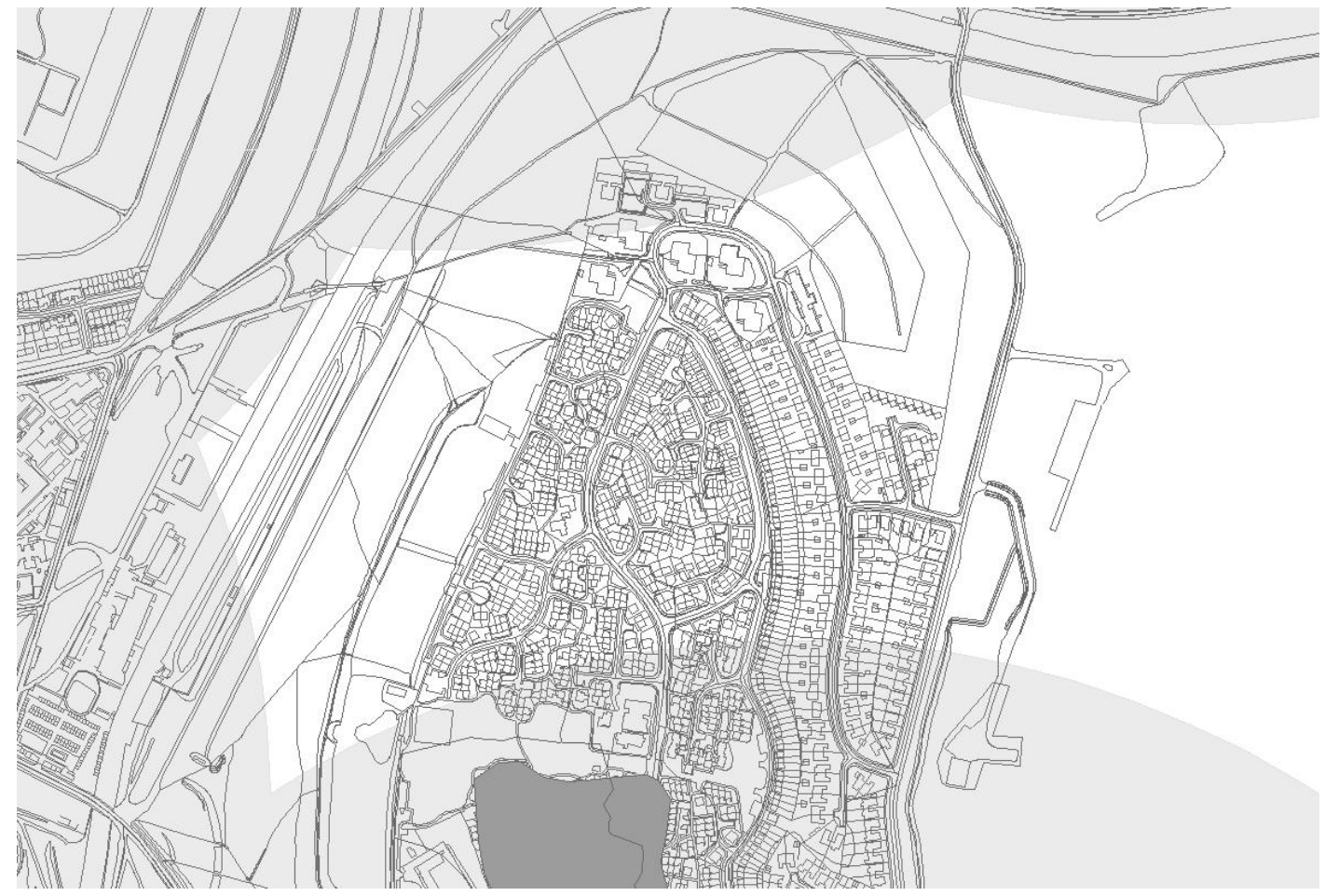

Fig. 2. An example of a recycling desert where residents have no access to kerbside recycling or a recycling centre as defined by BVPI 91. 


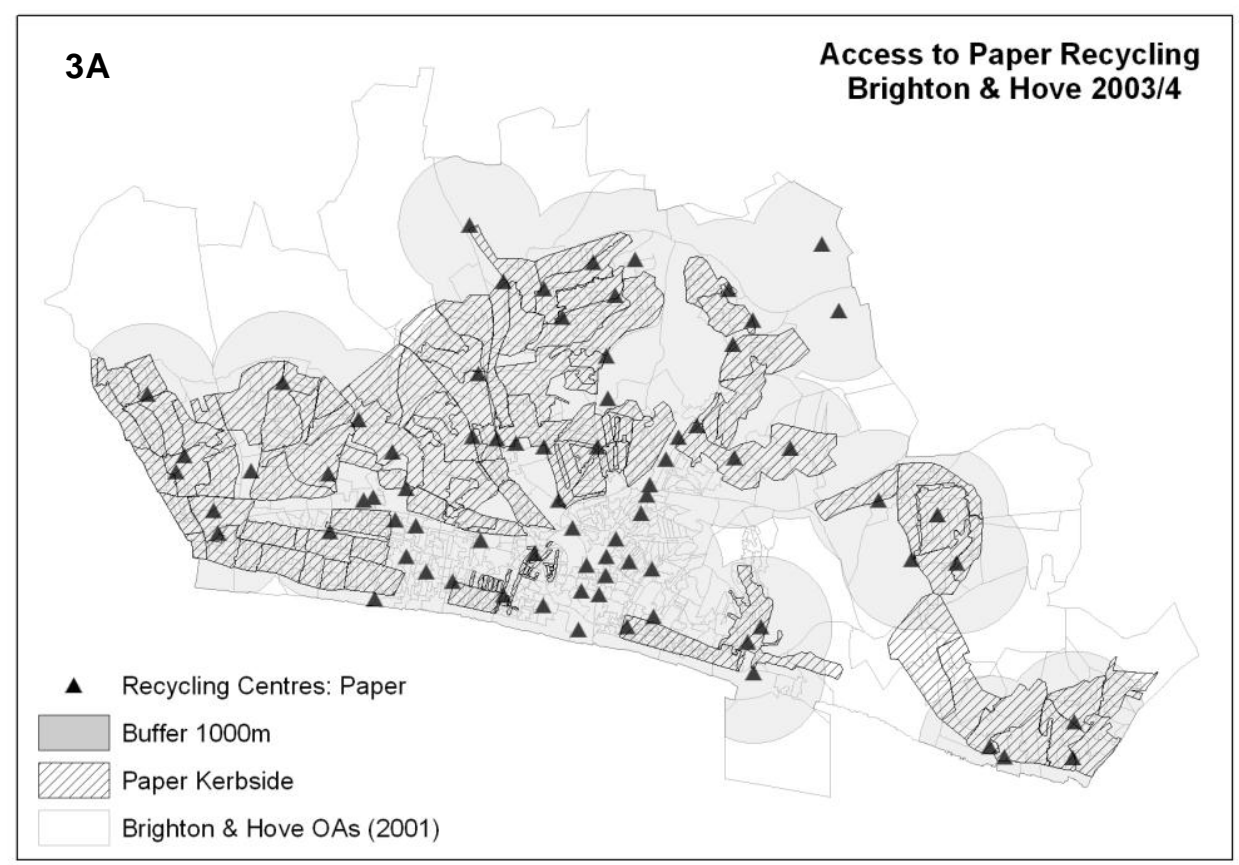

Fig. 3A-F. Spatial representation of the recycling services provided for different materials in Brighton \& Hove City, 2003/4. 


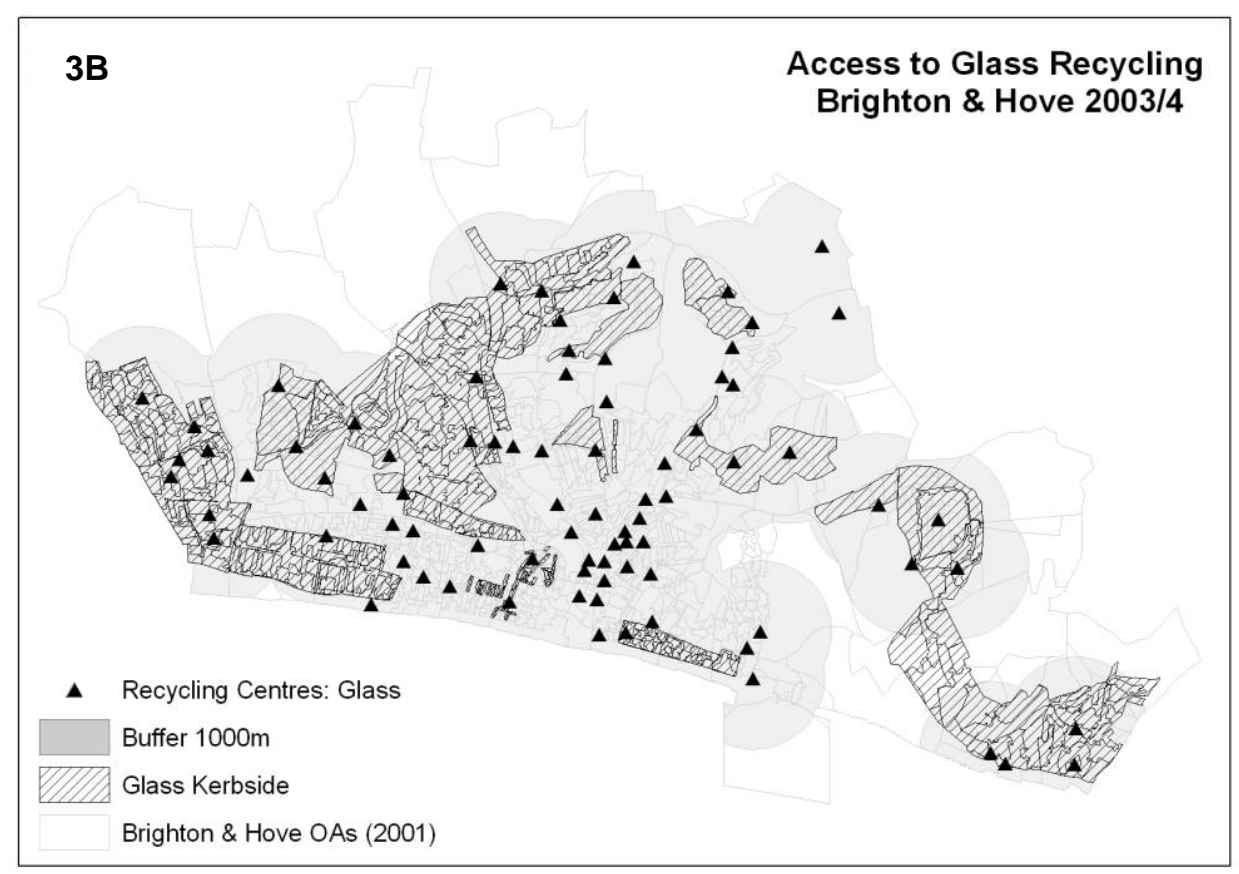




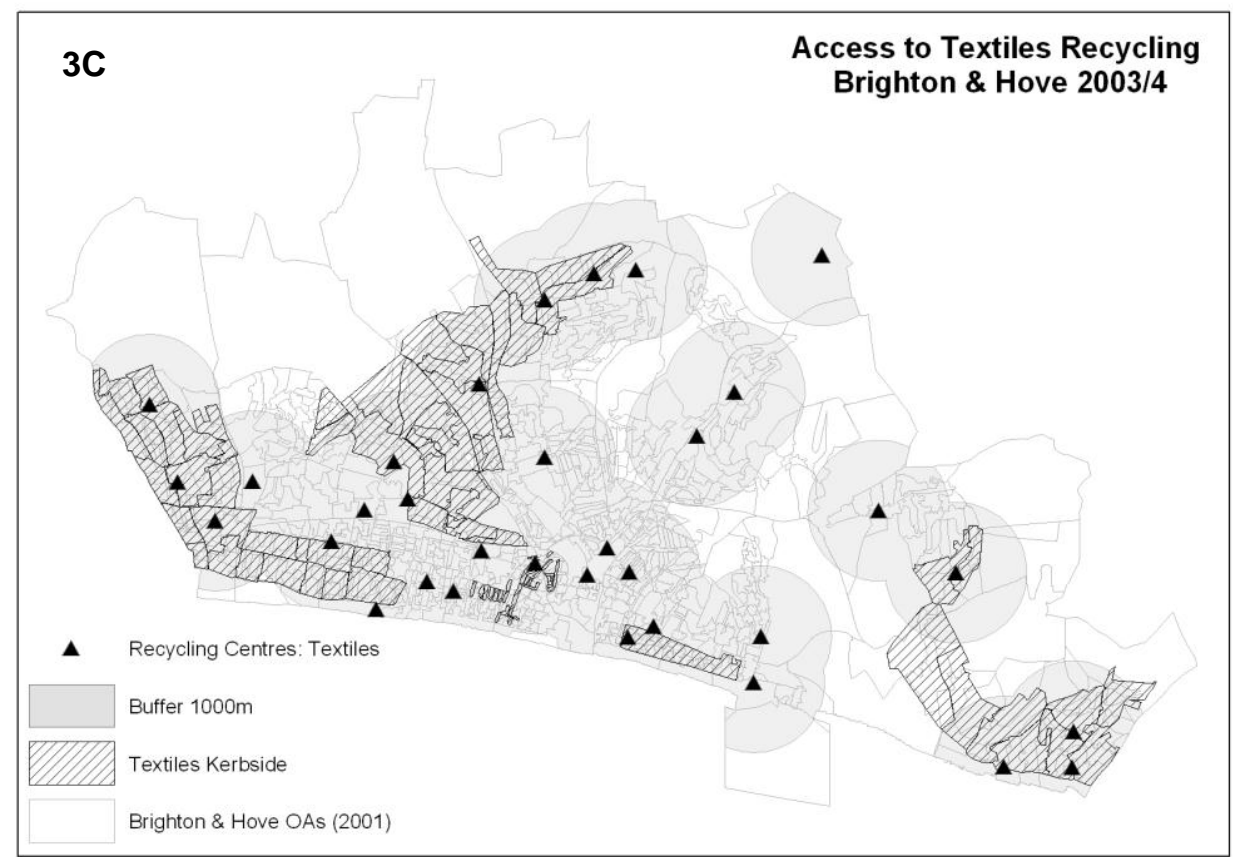




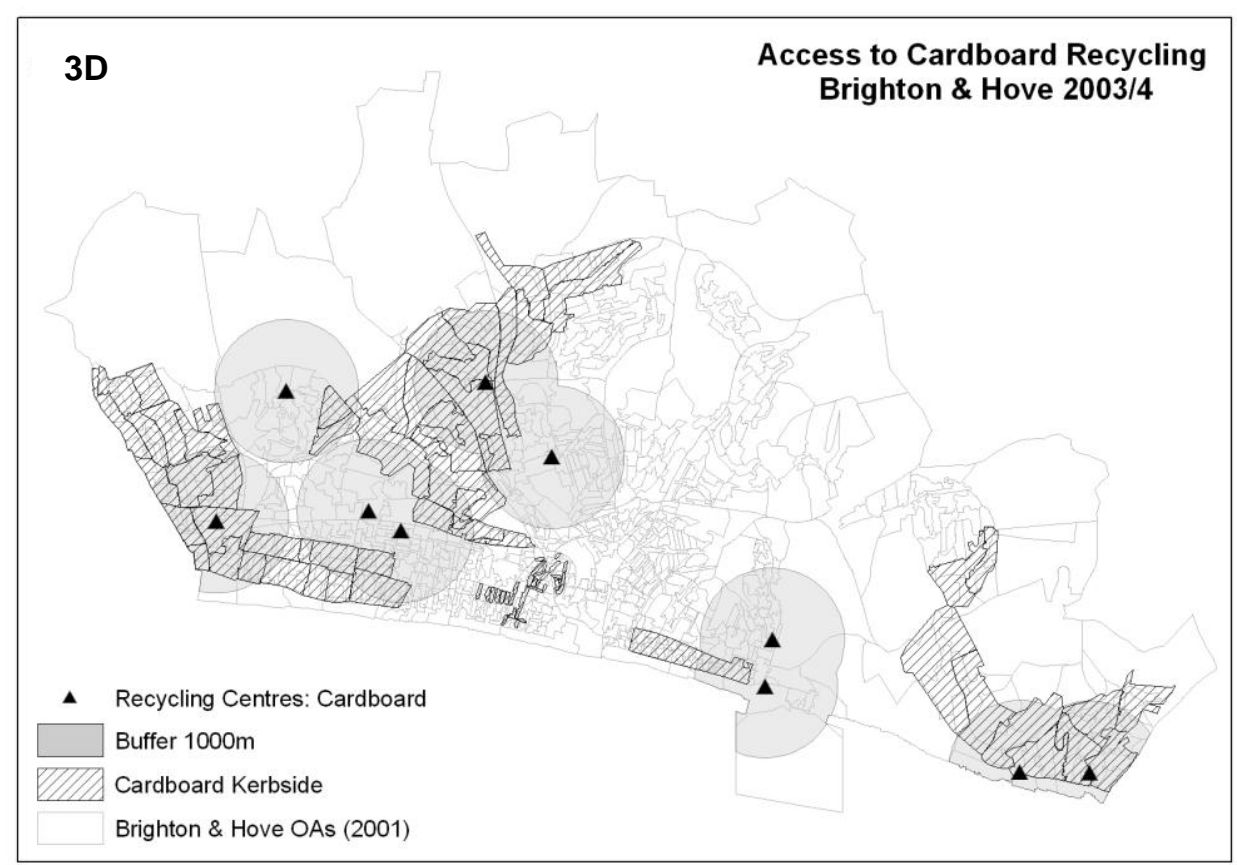




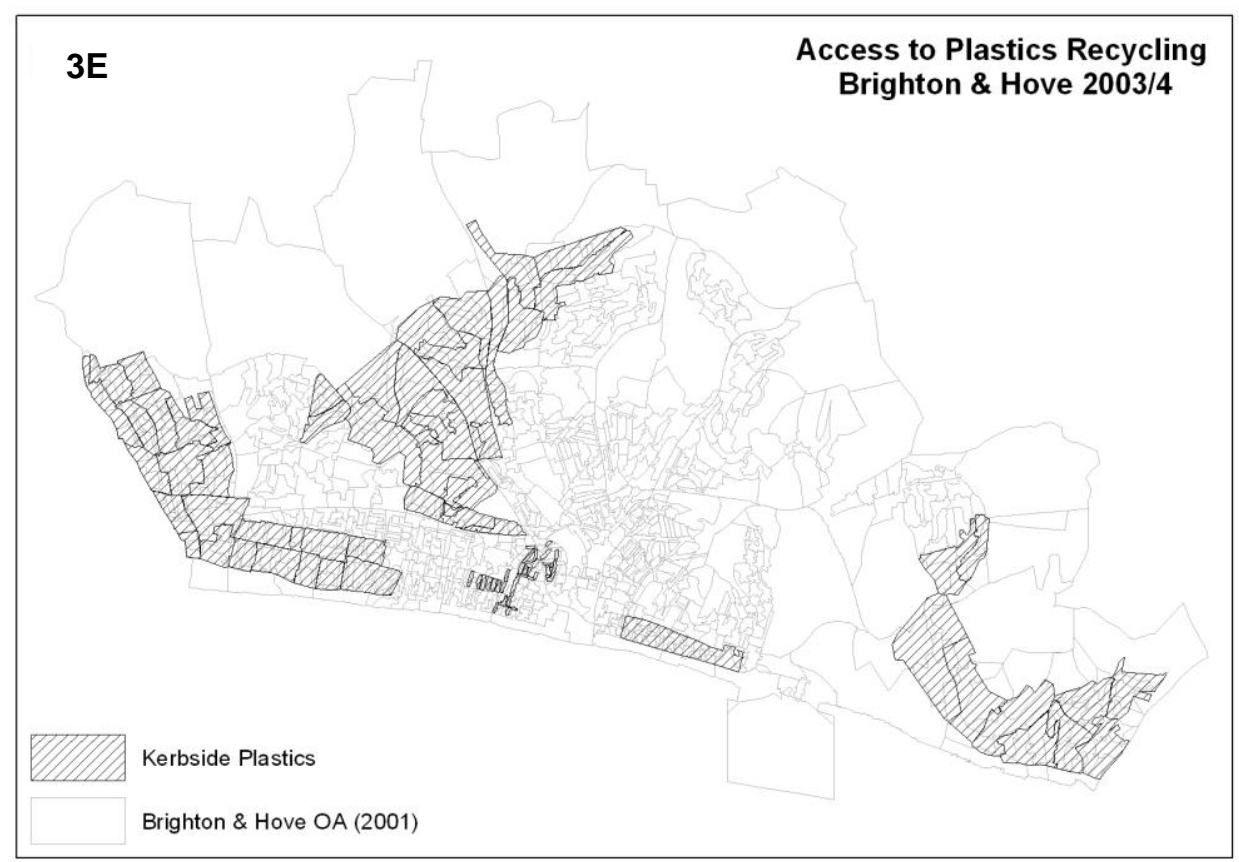




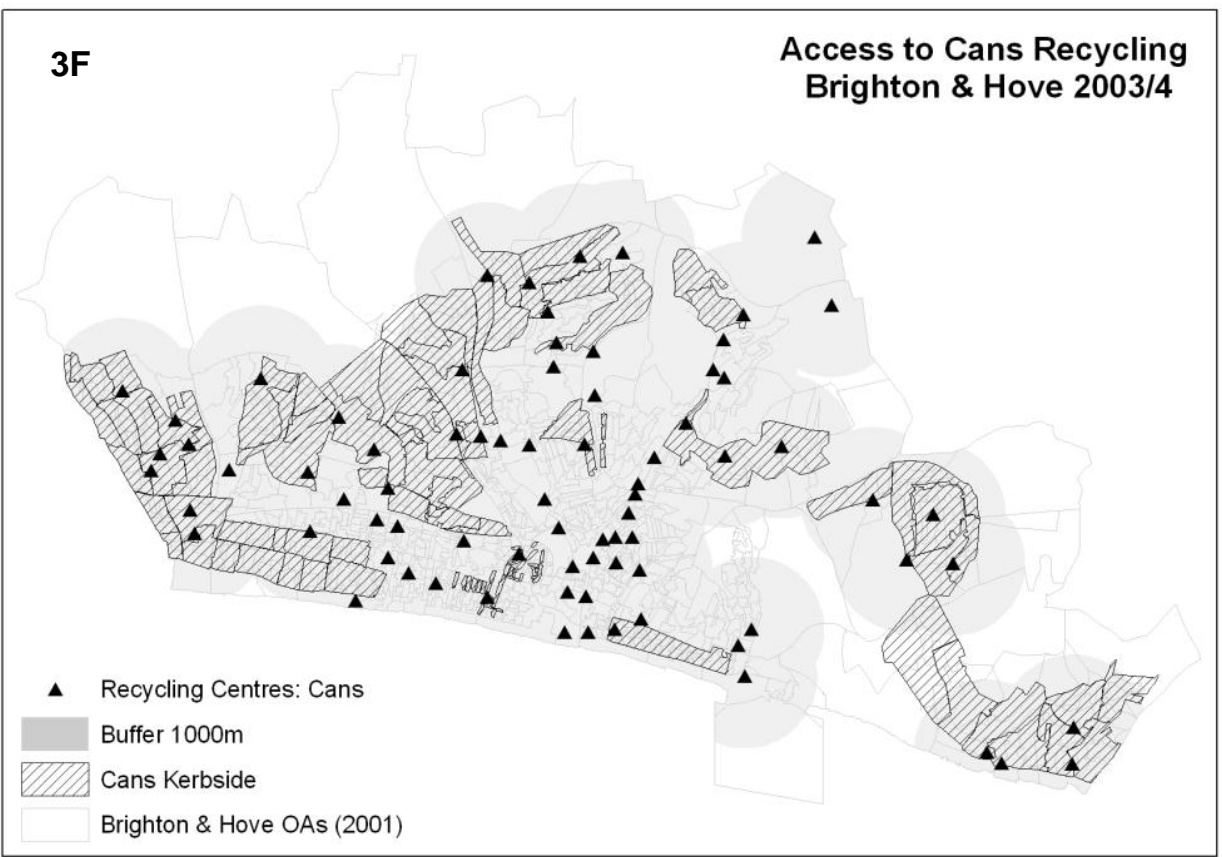




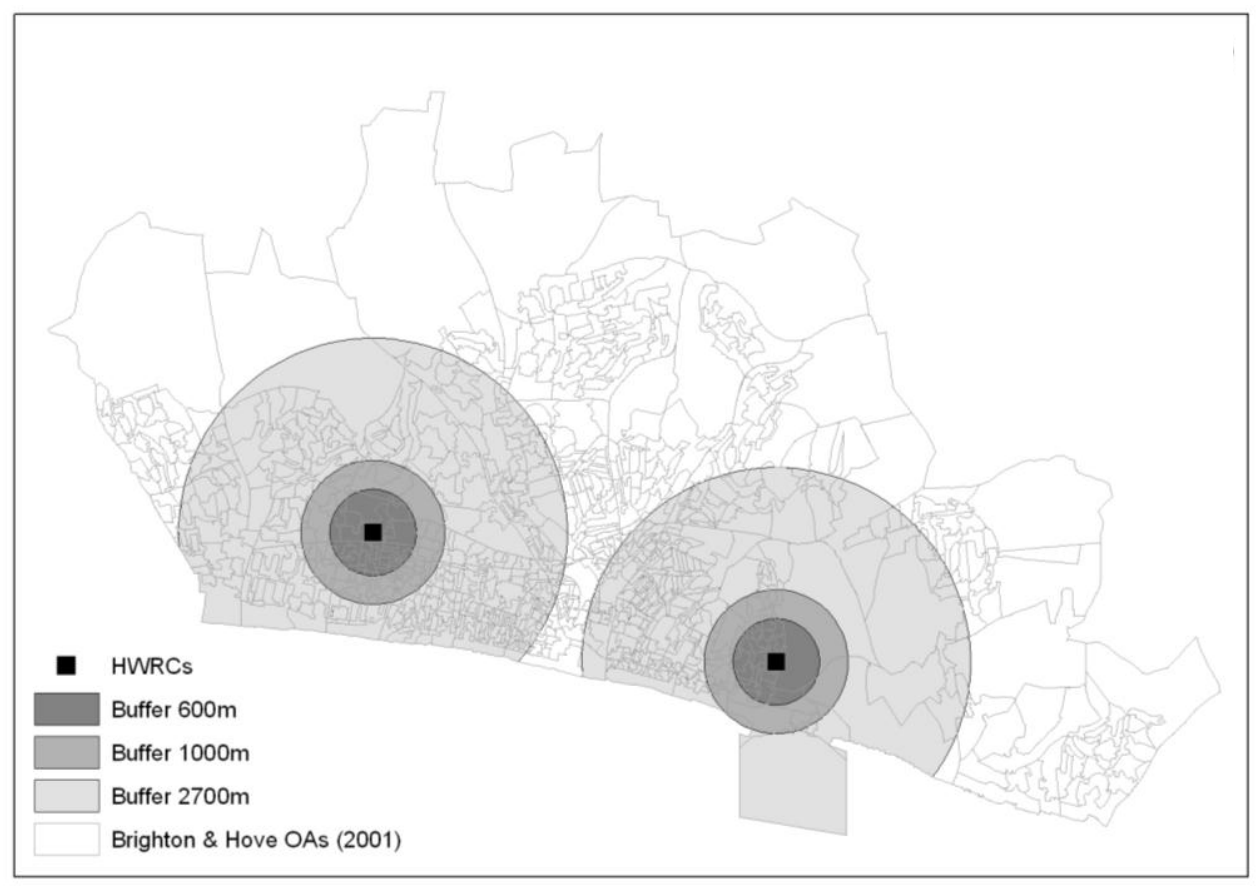

Fig. 4. Spatial representation of the recycling services provided for garden waste in Brighton \& Hove, 2003/4. 